\title{
Electrosynthesis and characterization of polymer films on silicon substrates for applications in micromanipulation
}

\author{
A. $\operatorname{Cot}^{1,2}$, , S. Lakard ${ }^{2, *}$, J. Dejeu ${ }^{3}$, P. Rougeot ${ }^{1}$, C. Magnenet ${ }^{2}$, B. Lakard ${ }^{2}$, M. Gauthier ${ }^{1}$
}

1 Institut FEMTO-ST, CNRS UFC ENSMM UTBM, AS2M Department, 24 rue Alain Savary, 25000 Besançon Cedex, France

2 Institut UTINAM, University of Franche-Comté, 16 route de Gray, 25030 Besançon Cedex, France

3 DCM, Département de Chimie Moléculaire, UMR CNRS 5250, ICMG FR - CNRS 2607, Université Joseph Fourier BP-53, 38041 Grenoble Cedex 9, France

\begin{abstract}
Aniline and p-phenylenediamine were electrochemically oxidized in aqueous solutions by potentiodynamic deposition using Cyclic Voltammetry (CV) technique Resulting polymer films electrodeposited on $\mathrm{Si}$ substrates were identified by infrared spectroscopy as polyaniline and poly(p-phenylenediamine) films. Cyclic voltammograms demonstrated that poly(p-phenylenediamine) films are non conductive contrary to polyaniline films which are conductive and electropolymerized through an autocatalytic mechanism. The morphological features (thickness, roughness, morphology) of the electrodeposited polymer films were determined using Profilometry, Scanning Electron Microscopy (SEM) and Atomic Force Microscopy (AFM). Adhesion force properties of polymer films were also studied by means of force-distance curves obtained by Atomic Force Microscopy. The influence of some experimental parameters (potential scan speed, number of potential scans) was also studied. Thus, it was shown that the potential scan speed strongly influence both morphological features and force adhesion, when the influence of the number of potential scans was less important. Under optimal conditions, it was possible to obtain very adhesive polymer films that could be useful for the micromanipulation of Si objects.
\end{abstract}




\section{Keywords}

Electropolymerization; Poly(p-phenylenediamine); Polyaniline; Morphological features; Adhesion forces.

*E-mail: sophie.lakard@univ-fcomte.fr, Phone : (33) 3816662 95, Fax : (33) 381666288.

\section{Introduction}

Conducting polymers have been a popular topic of investigation because of their interesting electrical and electrochemical properties and their potential applications in various areas. Among these are corrosion protection [1,2], electronic devices such as diodes [3], capacitors [4] or transistors [5], electrochromic displays [6], rechargeable batteries [7,8] and solid electrolytes [9], electrostatic materials [10], drug release systems [11, 12], electromechanical actuators [13], sensors $[14,15]$ or biosensors [16-18].

Conducting polymer films with a high conductivity and a high stability can be prepared either by chemical oxidation from a monomer solution in the presence of a strong oxidant or by electrochemical oxidation from a monomer solution in the presence of a supporting salt. Electrochemical polymerization is limited to metallic or semiconducting substrates but offers many advantages including its easiness, rapidity of the reaction, and possibility to accurately control the experimental conditions. Another attractive advantage of electrochemical deposition method for synthesizing conducting polymers is that the desired product may be anchored onto substrate materials at the desired quantity, shape and size for the final application in one single step. Hence, electrochemical methods to produce conducting polymer films have been extensively studied, in particular for electrodepositing polypyrrole, polythiophene or polyaniline, the most widely used conducting polymers [19-24].

Among conducting polymers, polyaniline $(\operatorname{PANI})[25,26]$ has been widely studied in the last decades due to its simple synthesis, good chemical stability in ambient environment, possibility of deposition on various substrates [27] and possibility of behaving like an insulator, a semiconductor or a metal, through chemical doping or dedoping process. Moreover, it is well-established that the polyaniline polymerization is dependent on various factors. For example, the temperature influences the films capacitance [28], the $\mathrm{pH}$ varies 
strongly the morphological features [29], and the nature of the counter-ions influences the conductivity of the polymer films [30].

Poly(p-phenylenediamine) (PPPD) is another heterocyclic polymer that can be obtained by oxidation in aqueous solution of p-phenylenediamine [31], whose structure differs from the structure of aniline from only one amino group. Poly( $p$-phenylenediamine) can be chemically or electrochemically deposited on surfaces or particles and it is often incorporated in sensors such as glucose sensors [32], $\mathrm{H}_{2} \mathrm{O}_{2}$ sensors [33] or nitrophenol sensors [34]. When compared to the large number of papers that have been written on the electropolymerization of aniline it is clear that relatively little work has been done on the polymerization of $\mathrm{p}$ phenylenediamine. The main studies concerned its polymerization mechanism [29], deposition kinetics [35], electrochemical properties [35] and spectroscopic properties [29, $36,37]$.

Due to the possibility of strongly depositing polyaniline and poly(p-phenylenediamine) on metallic or semiconducting surfaces, and due to the presence of amino groups able to modify the adhesion properties of the substrate, it is proposed in this work to electrosynthesize and to characterize these two amino polymers on silicon surfaces for further applications in micromanipulation. Indeed, in the field of micromanipulation research, the surface modification of silicon micromanipulators is an important issue to improve the catching and releasing of micro-objects. Micromanipulation being very dependent from adhesion properties, it is therefore important to control morphological features and adhesion properties of modified silicon surfaces. Consequently, in the present study, the effects on the morphological features and adhesion properties of electropolymerization parameters, such as the potential scan speed or the number of potential scans, were studied. In particular, electron microscopy and atomic force microscopy were used to deeply study PANI and PPPD films.

\section{Experimental}

\subsection{Reagents}

Analytical grade aniline, from Sigma Aldrich, was freshly distilled under reduced pressure and stored in dark at low temperature $\left(4^{\circ} \mathrm{C}\right)$. Double deionized water (Milli-Q, resistivity 18 
$\mathrm{M} \Omega . \mathrm{cm}$ ) and analytical grade hydrochloric acid were used to prepare the electrolyte solutions. Aniline was used at the concentration of $0.4 \mathrm{M}$ in an aqueous solution of $1.2 \mathrm{M}$ $\mathrm{HCl}$. Analytical grade p-phenylenediamine, from Sigma Aldrich, was used at the concentration of $0.1 \mathrm{M}$ in a commercial phosphate buffer solution $(\mathrm{pH} 7.0$, from Bioblock, France).

\section{Electrochemistry}

Potentiodynamic electropolymerization of polyaniline and poly( $p$-phenylenediamine) films was performed using a PGZ 301 potentiostat (Tacussel-Radiometer Analytical SA-France) controlled by a computer via VoltaMaster 4 Software interface. A three-electrode electrochemical cell was used in all cases. The rectangular planar substrates (area: $1.0 \mathrm{~cm} \mathrm{x}$ $0.5 \mathrm{~cm}$ ) used for polymer electrodeposition were obtained by cutting 100-oriented standard 4" silicon wafers (from Siltronix, B-doped, resistivity: $0.015 \pm 0.005 \Omega . \mathrm{cm}$, thickness: $250 \pm 10$ $\mu \mathrm{m})$. The reference electrode was a Saturated Calomel Electrode (SCE), XR100 model from Radiometer analytical and the counter-electrode was a platinum sheet. All electrochemical experiments were carried out at room temperature (293 K).

\subsection{Characterization}

The chemical structure of the films deposited by electrochemical oxidation of $p$ phenylenediamine and aniline was determined by using InfraRed Reflection Absorption Spectroscopy (IRRAS). More precisely, the samples were investigated in reflection geometry under a grazing-incidence angle of $71^{\circ}$ using a Vertex 70 FT-IR spectrometer equipped with a DTGS detector.

The thickness and roughness of each polymer film was determined by stylus-based mechanical probe profiler (Alpha-Step IQ, KLA Tencor). Thickness and average roughness were measured on a scan length of $1000 \mu \mathrm{m}$ at a scan speed of $20 \mu \mathrm{m} . \mathrm{s}^{-1}$.

The surface morphology of the polymer films was studied using a high-resolution Scanning Electron Microscope. Once synthesized and dried, polymer samples were examined in a LEO microscope (Scanning Electron Microscopy LEO stereoscan 440, manufactured by ZeissLeica, Köln, Germany) with an electron beam energy of $15 \mathrm{keV}$. 
The study of morphological features and adhesion properties was also performed with a commercial atomic force microscope (stand-alone SMENA scanning probe microscope NTMDT, Russian). The experiments were done under controlled environment with a laminar flow (humidity $30 \%$ and $25^{\circ} \mathrm{C}$ ). The force measurements performed on this Atomic Force Microscope were done in the "Nanorol platform" whose aim is to measure the micromanipulation nanoforces and which is based on the measurement of the AFM cantilever deformation with a laser deflection sensor. The Si rectangular AFM cantilever, whose stiffness is $0.3 \mathrm{~N} . \mathrm{m}^{-1}$, was fixed and the substrate moved vertically. The work application objectives are to improve reliability of micro-object manipulation, so interactions have been studied between a micrometric sphere and a plane. Force-distance curves were created to measure the approach force (pull-in force) when the sphere approaches the sample, and the adhesion force (pull-off force) when the sphere leaves the surface during sample retraction. Measurements were performed with a cantilever where a borosilicate sphere ( $r=5 \mu \mathrm{m}$ radius) was glued on the free extremity and below this one. Ten measurements were done at different points on the same sample with a driving speed of 0.2 $\mu \mathrm{m} . \mathrm{s}^{-1}$.

\section{Results and discussion}

\subsection{Electrodeposition of polymers}

Electrochemical deposition of polyaniline and poly(p-phenylenediamine) was performed by cyclic voltammetry on silicon substrates, from aqueous solutions of aniline and $p$ phenylenediamine, respectively. The influence of the potential scan speed and number of potential scans was studied for both polymers and the resulting measurements were discussed and relied to the morphological, structural and adhesion properties of the polymer films.

3.1.1. Electrodeposition of poly(p-phenylenediamine) films

Figure 1a shows the cyclic voltammogram of p-phenylenediamine (PPD) swept at $100 \mathrm{mV} . \mathrm{s}^{-1}$ during 10 scans in $\mathrm{pH} 7.0$ phosphate buffer solution containing $0.1 \mathrm{M}$ PPD at a Si (100) working electrode. During the first scan, oxidation peaks were observed at $+1.7 \mathrm{~V} / \mathrm{SCE}$ and + 2.0 V/SCE. The location and the broadness of these oxidation peaks are characteristic of 
amines, and the broadness renders the experimental study of the electrochemical mechanism impossible. Consequently, the two oxidation peaks can be attributed to the oxidation of the two amino groups contained in the molecular structure of PPD monomers. During the following scans, these oxidation peaks disappear and the oxidation currents decrease progressively, thus demonstrating that a non-conductive film grows on the surface of the Si electrode. The cyclic voltammogram also indicates that the electrochemical oxidation of PPD is a completely irreversible process.

Such electrochemical behavior was previously observed during the electropolymerization of PPD on Pt electrodes [29, 35], but also during the electropolymerization of other amines, for example ethylenediamine [38] or 1,3-diaminopropane [39]. Thus, it was shown that the anodic oxidation of PPD leads to the formation of poly( $p$-phenylenediamine) on platinum electrode. It was also proved using $a b$ initio calculations that the propagation sequence of the mechanism leading to poly(p-phenylenediamine) starts with an electron loss followed by a C-N cleavage and a deprotonation [29].

\subsubsection{Electrodeposition of polyaniline films}

Figure $1 \mathrm{~b}$ shows the cyclic voltammogram of aniline swept at $100 \mathrm{mV} \cdot \mathrm{s}^{-1}$ during 10 scans in an aqueous solution containing $0.4 \mathrm{M}$ aniline and $1.2 \mathrm{M} \mathrm{HCl}$ at a Si (100) working electrode. During the first scan, an oxidation peak was observed at $+1.8 \mathrm{~V} / \mathrm{SCE}$. This peak corresponds to the oxidation of the aniline monomers that initiated the electropolymerization of polyaniline (PANI) films. During the following scans, this anodic peak disappears and the oxidation currents increase progressively, thus demonstrating that a conductive film grows on the surface of the Si electrode. Moreover, the increase of the oxidation currents with the number of scans combined with the fact that the oxidation current starts to increase for smaller anodic potentials with number of scans, confirm the works from $\mathrm{Mu}$ et al. demonstrating that the electropolymerization of aniline is an autocatalytic process [40]. The cyclic voltammogram also indicates that the electrochemical polymerization of aniline is an irreversible process on Si electrodes.

This cyclic voltammogram was different from the ones usually obtained by electropolymerization of PANI on platinum electrodes that commonly exhibited well-defined 
redox peaks corresponding to a series of redox transitions: oxidation of the fully reduced insulating form to its radical cation (polaron), followed by oxidation of degradation products and/or intermediate species, and finally the transition from the delocalized polaronic state to a localized bipolaron or quinoid form $[41,42]$. This dependence to the substrate can be attributed to the difference of conductivity between $\mathrm{Si}$ and Pt surfaces, and also to the possible formation of a thin $\mathrm{SiO}_{2}$ layer on the $\mathrm{Si}$ working electrode rendering the electropolymerization more difficult on Si that on Pt substrates.

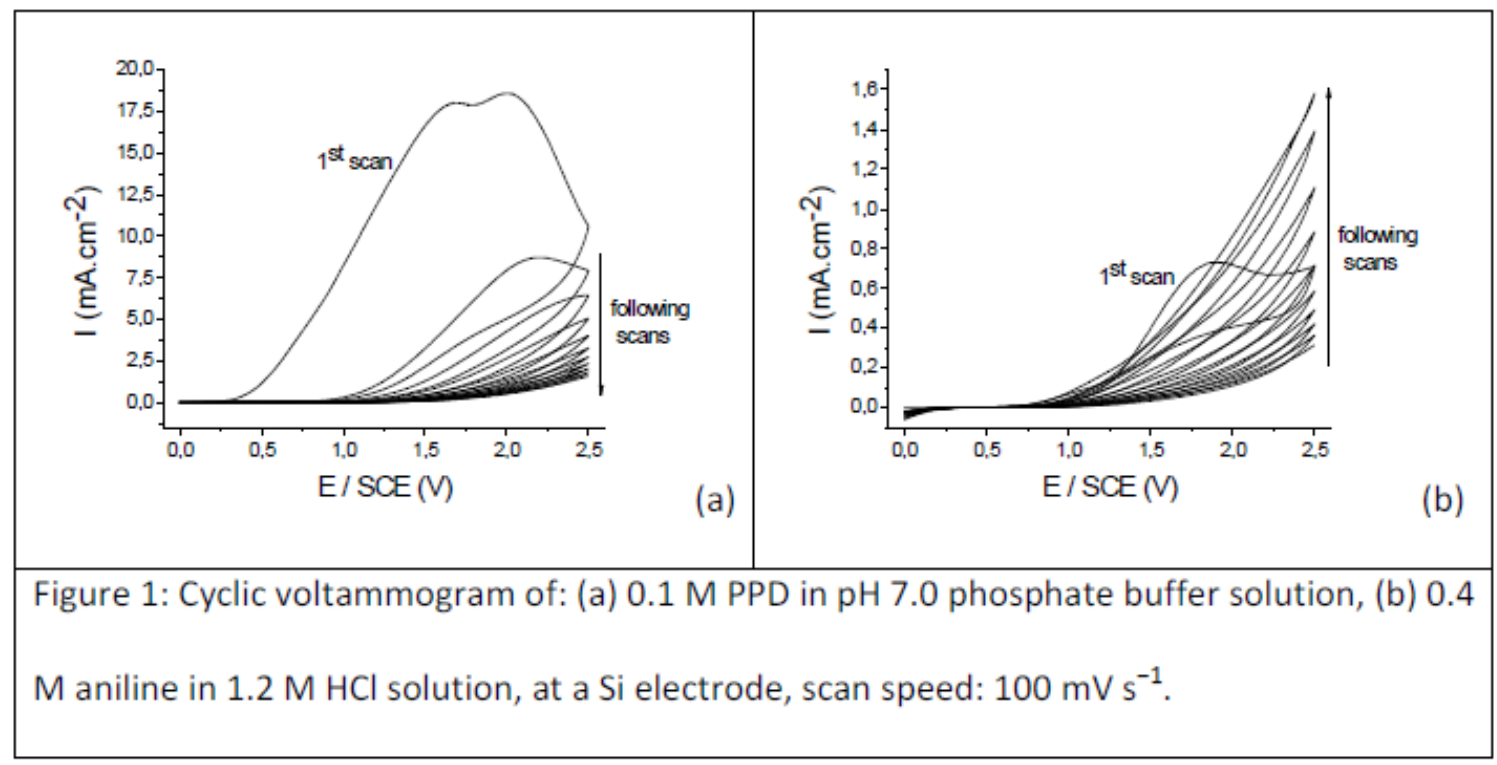

\subsection{Characterization of the polymer films}

3.2.1. Identification of the polymer films

InfraRed Reflection Absorption Spectroscopy (IRRAS) was used to check that the oxidation of PPD and aniline leads to the formation of poly(p-phenylenediamine) and polyaniline films on the Si substrates, respectively. Resulting IRRAS spectra were performed in the region of 4000 $-400 \mathrm{~cm}^{-1}$ at ambient temperature, and were obtained by subtracting the IR spectrum of each polymer film and the IR spectrum of the corresponding naked Si substrate. Table 1 gathers and assigns the different vibration bonds obtained in the IRRAS spectra of oxidized PPD and aniline. Thus, the infrared investigations show the presence of the characteristic vibration bonds of poly(p-phenylenediamine) and polyaniline, these vibration bonds being comparable due to the very similar structures of the two polymers. These vibration modes 
are the following ones: $\mathrm{N}-\mathrm{H}$ stretching of secondary amine (at $3306 \mathrm{~cm}^{-1}$ for PPPD and 3296 $\mathrm{cm}^{-1}$ for PANI), C-H aromatic and aliphatic stretching (near 3030, 2930 and $2860 \mathrm{~cm}^{-1}$ for both polymers), $\mathrm{C}=\mathrm{C}$ aromatic stretching (at 1600 and $1500 \mathrm{~cm}^{-1}$ ), $\mathrm{C}-\mathrm{H}$ deformation (at 1400 $\mathrm{cm}^{-1}$ ), C-N stretching (between 1200 and $1250 \mathrm{~cm}^{-1}$ ) and $=\mathrm{C}-\mathrm{H}$ deformation (at $1000 \mathrm{~cm}^{-1}$ ). Thus, these investigations confirm that the oxidation of PPD and aniline leads to poly(pphenylenediamine) and polyaniline, respectively.

\begin{tabular}{|l|c|c|}
\hline Vibration band assignment & Si/PPPD & Si/PANI \\
\hline N-H stretching (secondary amine) & $3306 \mathrm{~cm}^{-1}$ & $3296 \mathrm{~cm}^{-1}$ \\
\hline C-H aromatic stretching & $3031 \mathrm{~cm}^{-1}$ & $3024 \mathrm{~cm}^{-1}$ \\
\hline C-H aliphatic asymmetric stretching & $2926 \mathrm{~cm}^{-1}$ & $2941 \mathrm{~cm}^{-1}$ \\
\hline C-H aliphatic symmetric stretching & $2854 \mathrm{~cm}^{-1}$ & $2873 \mathrm{~cm}^{-1}$ \\
\hline C=C aromatic stretching & 1594 and $1497 \mathrm{~cm}^{-1}$ & 1618 and $1514 \mathrm{~cm}^{-1}$ \\
\hline C-H deformation & $1402 \mathrm{~cm}^{-1}$ & $1378 \mathrm{~cm}^{-1}$ \\
\hline C-N stretching & $1248 \mathrm{~cm}^{-1}$ & $1215 \mathrm{~cm}^{-1}$ \\
\hline =C-H deformation & $1002 \mathrm{~cm}^{-1}$ & $963 \mathrm{~cm}^{-1}$ \\
\hline
\end{tabular}

Table 1: Infrared vibration bands of oxidized PPD and aniline.

\subsubsection{Morphological features and adhesion of the polymer films}

\subsection{2.a. Poly(p-phenylenediamine)}

$\square$ Thickness and Roughness:

The thickness and roughness of the poly(p-phenylenediamine) samples were measured on a scale length of $1000 \mu \mathrm{m}$ using a stylus-based mechanical probe profiler enabling surface mechanical scanning without damaging it. To estimate the thickness, the probe was moved from the Si substrate to the polymer film through the substrate/polymer interface and the height difference between the Si substrate and the polymer was estimated. Logically, the increase of the potential scan speed leads to a decrease of the thickness of the polymer films from $11.9 \mu \mathrm{m}$ at $50 \mathrm{mV} . \mathrm{s}^{-1}$ to $2.3 \mu \mathrm{m}$ at $200 \mathrm{mV} . \mathrm{s}^{-1}$, considering only polymer films obtained after 10 potential scans. Increasing the number of potential scans from 5 to 15 also results logically in an increase of the polymer thickness, from $2.2 \mu \mathrm{m}$ for 5 scans to $7.9 \mu \mathrm{m}$ for 15 
scans, considering only polymers electrodeposited at $100 \mathrm{mV} . \mathrm{s}^{-1}$. The average roughness was also measured by moving the probe inside the polymer film on a distance of $1000 \mu \mathrm{m}$. The resulting roughness were not very different from one sample to the other. Indeed, all the measured roughness were comprised between 0.1 and $0.4 \mu \mathrm{m}$, except the thickest poly(pphenylenediamine) film whose roughness was estimated to $0.6 \mu \mathrm{m}$. All these thickness and roughness measurements were repeated 5 times and the values gathered in Table 2 are the averaged ones.

\begin{tabular}{|c|c|c|}
\hline Operating conditions & Thickness (in $\mu \mathrm{m})$ & Roughness (in $\mu \mathrm{m})$ \\
\hline $50 \mathrm{mV} . \mathrm{s}^{-1}-10$ scans & $11.9 \pm 0.5$ & $0.6 \pm 0.2$ \\
\hline $100 \mathrm{mV} . \mathrm{s}^{-1}-10$ scans & $5.6 \pm 0.3$ & $0.4 \pm 0.1$ \\
\hline $160 \mathrm{mV} . \mathrm{s}^{-1}-10$ scans & $2.6 \pm 0.2$ & $0.3 \pm 0.1$ \\
\hline $200 \mathrm{mV} . \mathrm{s}^{-1}-10$ scans & $2.3 \pm 0.2$ & $0.3 \pm 0.1$ \\
\hline $100 \mathrm{mV} . \mathrm{s}^{-1}-5$ scans & $2.2 \pm 0.2$ & $0.3 \pm 0.1$ \\
\hline $100 \mathrm{mV} . \mathrm{s}^{-1}-15$ scans & $7.9 \pm 0.3$ & $0.3 \pm 0.1$ \\
\hline
\end{tabular}

Table 2: Thickness and roughness of electrodeposited poly(p-phenylenediamine) films.

\section{$\square$ Morphology:}

As previously shown, poly(p-phenylenediamine) films (PPPD) were grown on Si substrates by sweeping the potential during 10 scans at different scan speeds comprised between 50 and $200 \mathrm{mV} . \mathrm{s}^{-1}$. Figure 2 shows the SEM micrographs of PPPD films grown by using the different scan speeds. Using a scan rate of $50 \mathrm{mV} . \mathrm{s}^{-1}$ resulted in a dendritic growth of polymer films on the Si substrates leading to a coral-like needle structure (Fig. 2a). More precisely, the polymer-modified surface consisted of nanoneedle networks formed by interconnection of individual needles. Furthermore, the needles appeared randomly distributed on the substrate leading to an inhomogeneously coated surface. The morphology of the PPPD films grown at $100 \mathrm{mV} . \mathrm{s}^{-1}$ was not very different and the same coral-like needle structure was revealed (Fig. 2b). However, the number of needles deposited on the substrate seemed lower and the surface appeared more homogeneously coated by the polymer film. The structures obtained at higher scan rates (160 and $\left.200 \mathrm{mV} . \mathrm{s}^{-1}\right)$ were slightly different since the individual needles were more difficult to observe (Fig. $2 c$ and $2 d$ ). In fact, the structure of 
the polymer films appeared less structured and resulted in an amorpheous surface made of interwined not well-defined nanoneedles. It also seemed that these latter coatings covered the whole surface contrary to the polymer films electrosynthesized at lower scan rates that were randomly and inhomogenously distributed on the surface.

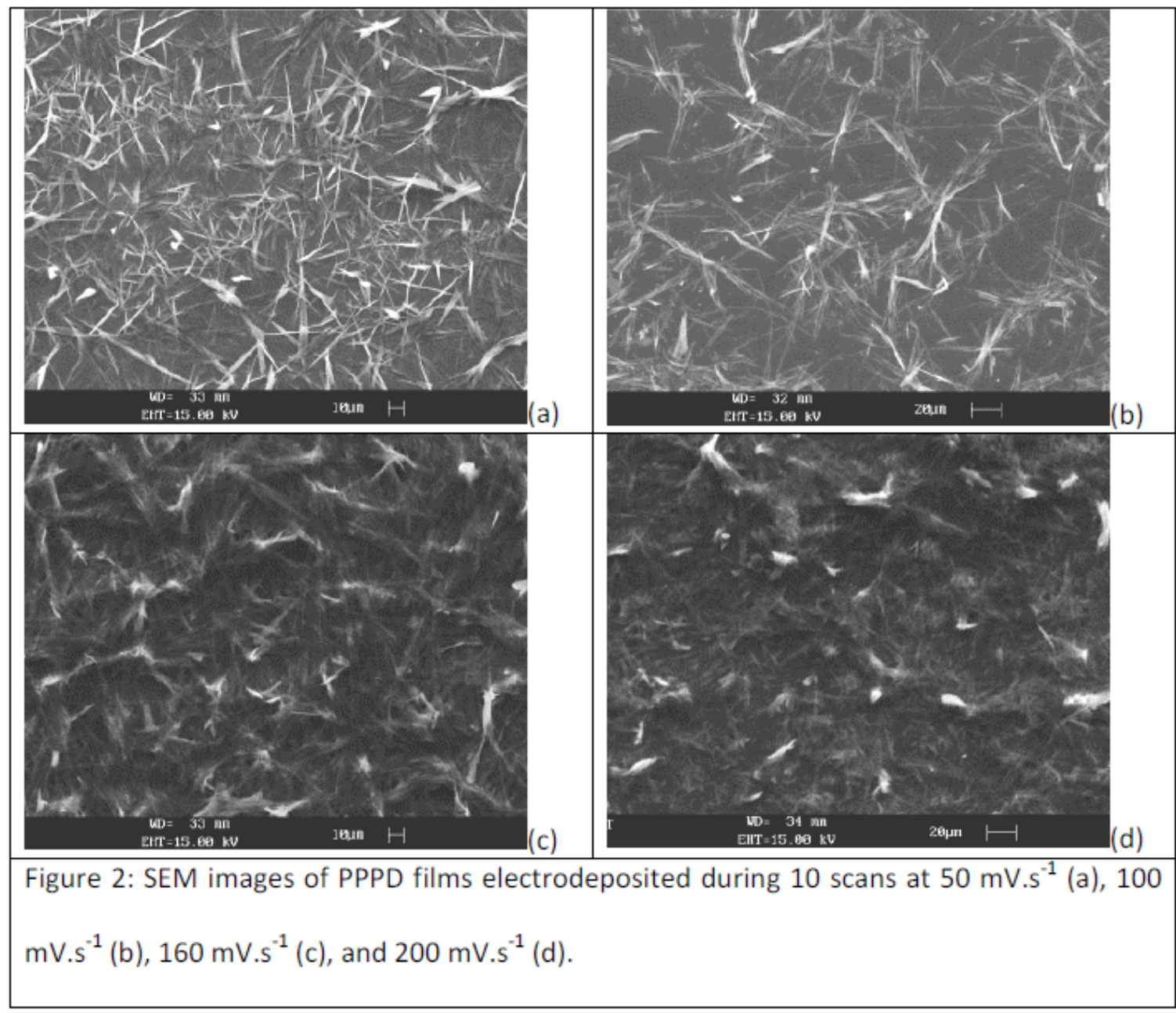

To obtain additional information, the morphology of PPPD films grown at different potential scan speeds was also studied by atomic force microscopy (Figure 3). The sizes of the polymer surfaces scanned by using AFM were $20 \mu \mathrm{m} \times 20 \mu \mathrm{m}$ contrary to SEM pictures that imaged areas of several hundred of micrometers. Consequently, the information that can be deduced from the AFM and SEM imaging were different and complementary.

Concerning AFM images, it could be observed that PPPD films electrodeposited at high scan speed (160 and $200 \mathrm{mV} . \mathrm{s}^{-1}$ ) led to relatively smooth surfaces since the height of the highest 
mountains composing the surface structure are not higher than $0.5 \mu \mathrm{m}$ (Figure $3 \mathrm{c}$ and $3 \mathrm{~d}$ ). PPPD films electrodeposited at low speed (50 and $100 \mathrm{mV} \cdot \mathrm{s}^{-1}$ ) led to mountains having a slightly higher size (comprised between 1 and $2 \mu \mathrm{m}$ ). This is in agreement with the roughness values obtained through profilometric measurements since the average roughness was found to increase when the potential scan speed decreases (Table 1). In addition AFM shows that the Si substrate is not entirely coated by the polymer film whatever the potential scan speed is. It also indicates that the surface of the film presents a high porosity due to the intertwined nanoneedle network.

To test the influence of the thickness, different PPPD films were electrodeposited using the same scan speed $\left(100 \mathrm{mV} . \mathrm{s}^{-1}\right)$ but by doing 5,10 or 15 potential scans. Doing this, PPPD films having thickness from $2.2 \mu \mathrm{m}$ to $5.6 \mu \mathrm{m}$ were grown on the Si substrates. However, the morphology of the polymer films remains unchanged since the AFM and SEM images exhibit a morphology consisted of nanoneedle networks whatever the number of scans used (Supplementary File 1). The roughness of these samples was also similar since it only varies from 0.3 to $0.4 \mu \mathrm{m}$ depending on the number of scans.

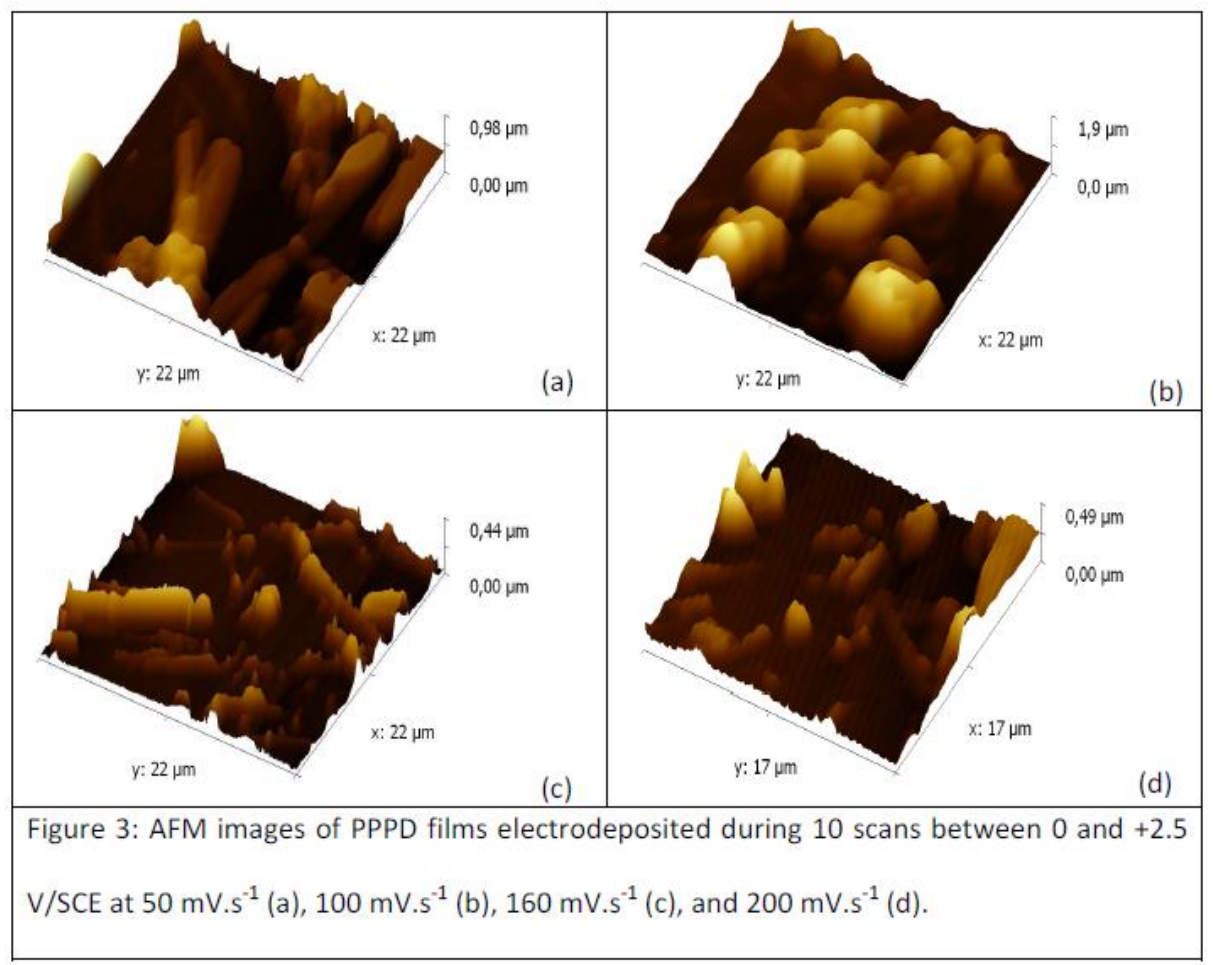




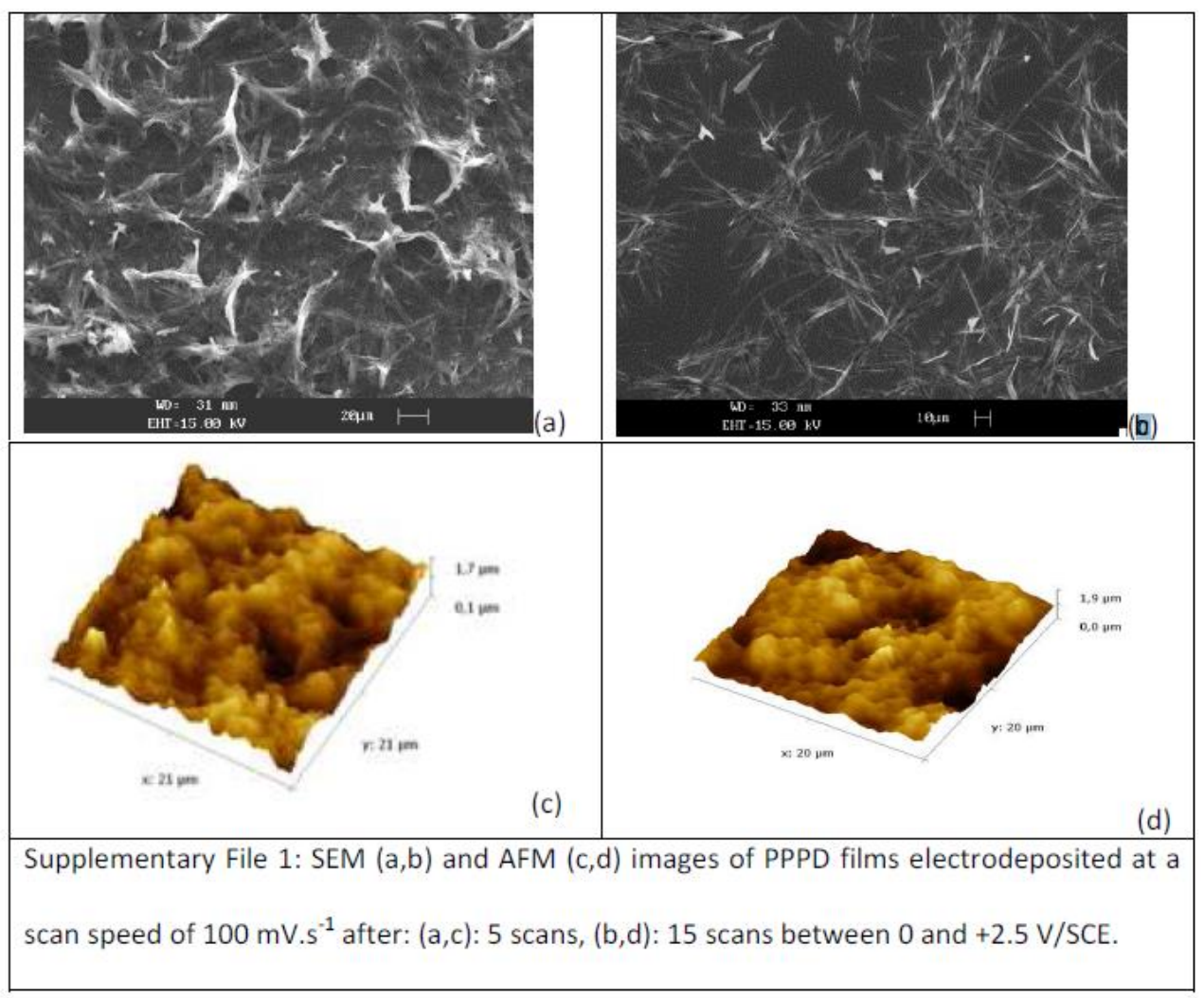

Force measurements:

The adhesion force, so called pull-off force, was measured for all poly(p-phenylenediamine) films as a function of the electrodeposition conditions. The pull-off force was measured through AFM force-distance curves. More precisely a borosilicate sphere glued at the extremity of the AFM cantilever approached the polymer sample and the pull-off force was measured when the sphere leaved the surface during polymer sample retraction. Then experimental force-distance curves were analyzed and the average pull-off forces were gathered in Table 3. These measurements prove that the functionalization of the Si substrates leads to a strong decrease of the adhesion force since the pull-off measured between the cantilever and the PPPD-modified Si substrates was more than ten times less than the one measured for naked Si substrates. Furthermore, the experimental data of Table 3 indicate a strong influence of the scan speed on the pull-of adhesion properties. Indeed, the pull-off force increases continuously from $-61.5 \mathrm{nN}$ at a scan rate of $50 \mathrm{mV} . \mathrm{s}^{-1}$ to -122.6 $\mathrm{nN}$ at a potential scan speed of $200 \mathrm{mV} \cdot \mathrm{s}^{-1}$. The influence of the number of scans, for a given scan rate, on the pull off force was also studied. Similar pull off forces were measured since 
they were all comprised between - 74.8 and $78.2 \mathrm{nN}$, thus demonstrating that the number of potential scans has no influence on the adhesion properties.

These results seem to indicate that the thickness is not the key factor. Indeed, the 3 samples electrodeposited at $100 \mathrm{mV} . \mathrm{s}^{-1}$ have a thickness varying from $2.2 \mu \mathrm{m}$ to $11.9 \mu \mathrm{m}$ but have similar adhesion forces. On the contrary, it is possible that the roughness has an impact on the adhesion properties. Indeed when the scan speed increases, the roughness continuously decreases and the adhesion force continuously increases. However, contrary to the changes in adhesion forces, the changes in roughness are rather low and it could be believed that the roughness is not the only factor impacting the adhesion properties of the PPPD films. The other factor that seems to influence the adhesion forces is the morphology since it was proved through AFM and SEM microscopy that the morphology changes depending on the potential scan speed. In particular, it appears that high adhesion forces are obtained for high potential scan speed corresponding to thin homogeneous polymer-modified substrates when the low adhesion forces are obtained for low potential scan speed corresponding to thick polymer films composed of well-defined nanoneedles inhomogeneously distributed on the Si substrates.

To conclude it appears that the adhesion force of $\mathrm{Si}$ is strongly modified by electrodeposition of poly(p-phenylenediamine). Furthermore the adhesion forces can be adjusted by varying the electropolymerization conditions. In particular, in the case of PPPD, it seems that the adhesion force is dependent on the morphology and roughness but not dependent on the thickness of the polymer film.

\begin{tabular}{|c|c|}
\hline Operating conditions & Pull-off Force \\
\hline naked $\mathrm{Si}$ & $1 \mu \mathrm{N}$ \\
\hline $50 \mathrm{mV} . \mathrm{s}^{-1}-10$ scans & $-61.5 \mathrm{nN}$ \\
\hline $100 \mathrm{mV} \cdot \mathrm{s}^{-1}-10$ scans & $-74.8 \mathrm{nN}$ \\
\hline $160 \mathrm{mV} \cdot \mathrm{s}^{-1}-10$ scans & $-90.5 \mathrm{nN}$ \\
\hline $200 \mathrm{mV} \cdot \mathrm{s}^{-1}-10$ scans & $-122.6 \mathrm{nN}$ \\
\hline $100 \mathrm{mV} . \mathrm{s}^{-1}-5$ scans & $-74.9 \mathrm{nN}$ \\
\hline $100 \mathrm{mV} \cdot \mathrm{s}^{-1}-15$ scans & $-78.2 \mathrm{nN}$ \\
\hline
\end{tabular}

Table 3: Average measured pull off force values of PPPD films. 


\subsection{2.b. Polyaniline:}

$\square$ Thickness and Roughness:

Profilometry was used to measure the thickness and roughness of the electrodeposited polyaniline (PANI) films following the same procedure than for the poly(pphenylenediamine) films. Decreasing the potential scan speed resulted logically in an increase of the polyaniline film thickness (from $1.3 \mu \mathrm{m}$ at $200 \mathrm{mV} . \mathrm{s}^{-1}$ to $242.4 \mu \mathrm{m}$ at $5 \mathrm{mV} . \mathrm{s}^{-}$ $\left.{ }^{1}\right)$. Considering the same range of potential scan speeds, it can be noticed that the increase of the polymer film thickness is higher for PANI films (from $1.3 \mu \mathrm{m}$ at $200 \mathrm{mV} . \mathrm{s}^{-1}$ to $18.7 \mu \mathrm{m}$ at $50 \mathrm{mV} . \mathrm{s}^{-1}$ than for PPPD films (from $2.3 \mu \mathrm{m}$ at $200 \mathrm{mV} . \mathrm{s}^{-1}$ to $11.9 \mu \mathrm{m}$ at $200 \mathrm{mV} . \mathrm{s}^{-1}$ ). This is due to the fact that PANI films are more conductive than PPPD films as previously deduced from the cyclic voltammograms. The number of potential scans was also changed to further study the effect of the thickness of polymer films grown at the same potential scan speed. The measured thicknesses varied from $2.9 \mu \mathrm{m}$ to $7.2 \mu \mathrm{m}$ when the number of potential scans was increased from 5 to 15 . The average roughness of each PANI sample was also measured using profilometry. The roughness values were comprised between 0.1 and $0.5 \mu \mathrm{m}$, depending on the electrodeposition parameters. The general trend indicates that the roughness increases when the thickness increases or the potential scan speed decreases.

\begin{tabular}{|c|c|c|}
\hline Operating conditions & Thickness (in $\mu \mathrm{m})$ & Roughness (in $\mu \mathrm{m}$ ) \\
\hline $5 \mathrm{mV} . \mathrm{s}^{-1}-10$ scans & $242.4 \pm 5.0$ & $0.5 \pm 0.2$ \\
\hline $10 \mathrm{mV} . \mathrm{s}^{-1}-10$ scans & $119.5 \pm 2.0$ & $0.4 \pm 0.2$ \\
\hline $20 \mathrm{mV} . \mathrm{s}^{-1}-10$ scans & $52.1 \pm 1.0$ & $0.5 \pm 0.2$ \\
\hline $50 \mathrm{mV} . \mathrm{s}^{-1}-10$ scans & $18.7 \pm 0.5$ & $0.3 \pm 0.1$ \\
\hline $100 \mathrm{mV} . \mathrm{s}^{-1}-10$ scans & $5.7 \pm 0.2$ & $0.2 \pm 0.1$ \\
\hline $200 \mathrm{mV} . \mathrm{s}^{-1}-10$ scans & $1.3 \pm 0.1$ & $0.1 \pm 0.1$ \\
\hline $100 \mathrm{mV} . \mathrm{s}^{-1}-5$ scans & $2.9 \pm 0.2$ & $0.3 \pm 0.1$ \\
\hline $100 \mathrm{mV} . \mathrm{s}^{-1}-15$ scans & $7.2 \pm 0.3$ & $0.3 \pm 0.1$ \\
\hline
\end{tabular}

Table 4: Thickness and roughness of electrodeposited polyaniline films.

$\square$ Morphology: 
For comparison another heterocyclic polymer containing amino groups was electrodeposited on Si substrates at different potential scan rates comprised between 5 and $200 \mathrm{mV}^{-1} \mathrm{~s}^{-1}$. The morphology of these polyaniline films was determined as a function of the scan speed using electronic microscopy (Figure 4). In all cases, the polymer films exhibit a porous structure and a sponge-like structure. More precisely, this structure consists in a network of individual nanowires. Maybe this structure is more difficult to observe for the highest scan speed (200 $\left.\mathrm{mV} . \mathrm{s}^{-1}\right)$, probably because the amount of polymer electrodeposited on the Si substrate is not enough important to produce a well-defined structure. Furthermore, when the potential scan speed decreases, the number of electron exchanged between the monomer solution and the Si substrate increases leading to the coverage of the whole substrate and to an increase of the thickness. It is also visible that more details of the polyaniline structure can be observed when the potential scan speed is decreased despite the fact that the same magnification was used for imaging all polymer samples. That is why it is possible to observe the granularities of the structure in Figure 4a. The sponge-like structure of polyaniline has already been observed in the literature and is typical of this polymer when it is synthesized by electrochemistry $[25,28]$. It is interesting to notice that the porous structure is observed even at high scan speed and so that the structure is not dependant on the potential scan speed contrary to the structure of PPPD films. It can also be mentioned that the structure of PPPD and PANI is strongly different although they have a very similar chemical structure.

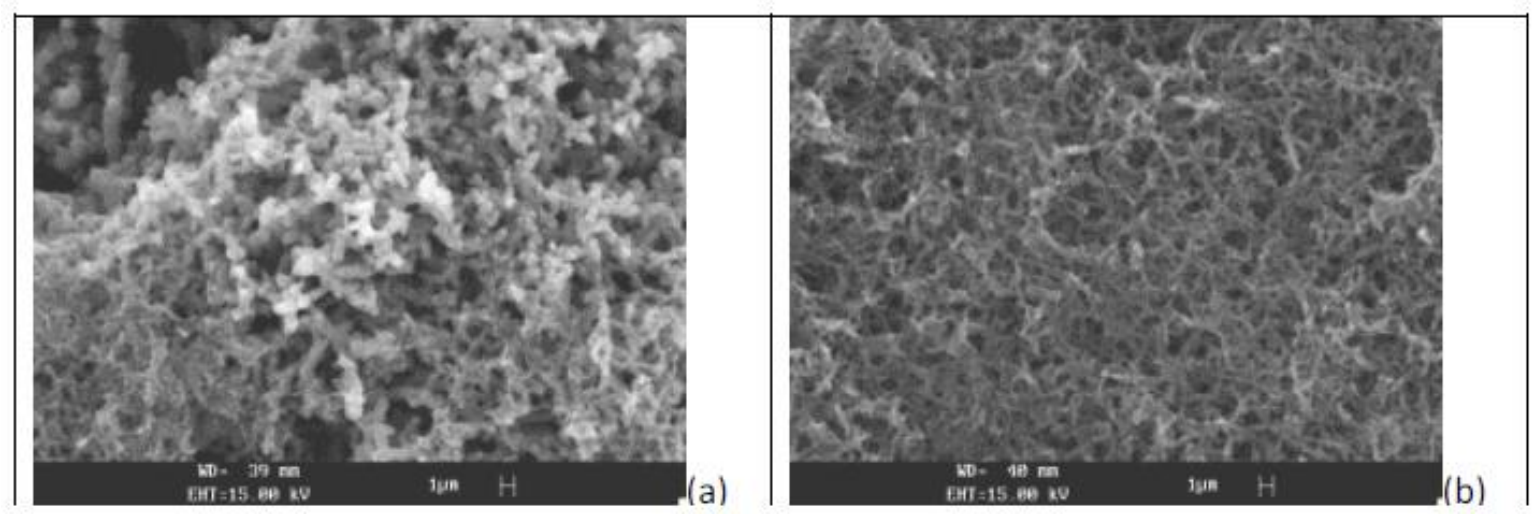



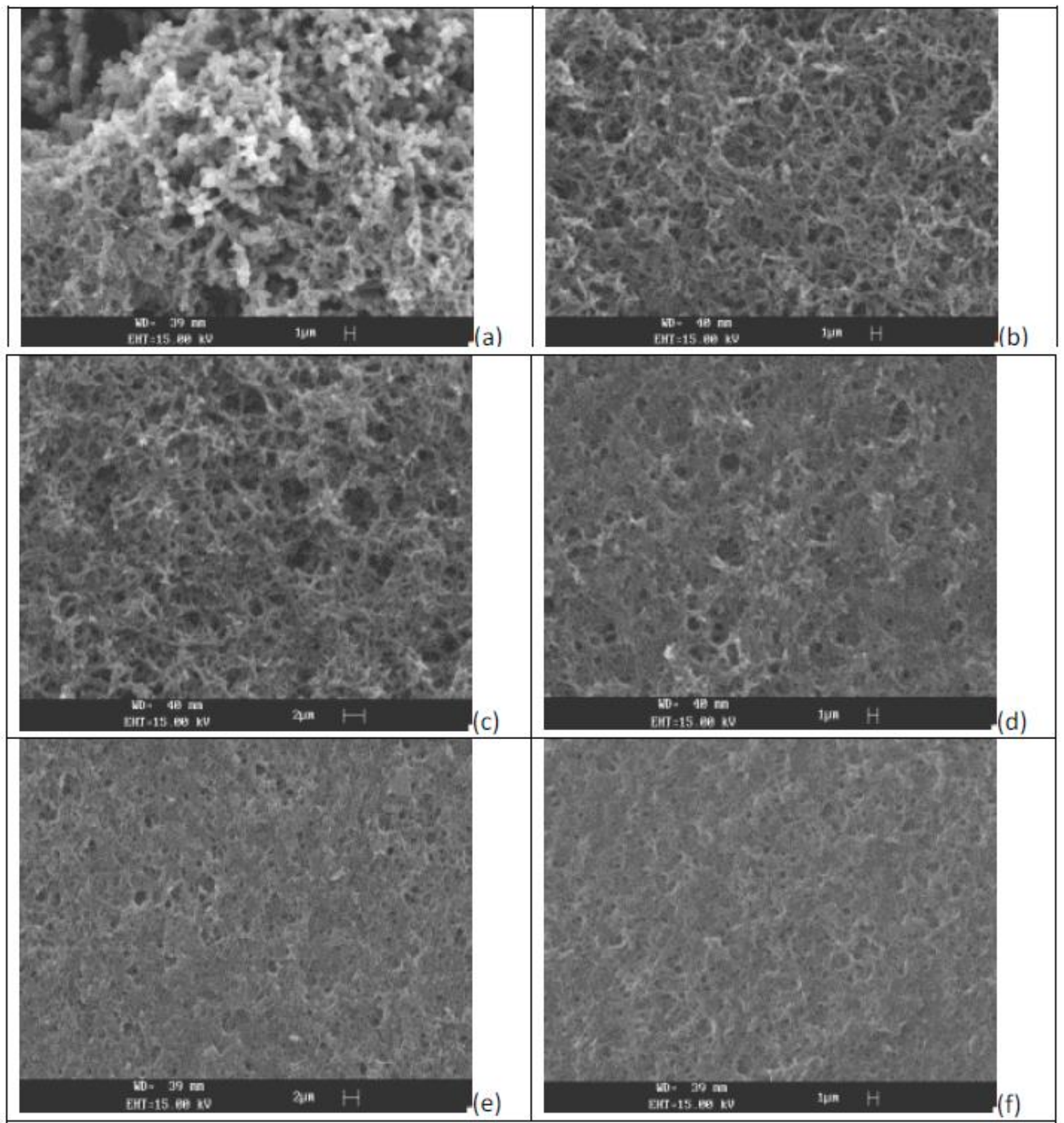

Figure 4: SEM images of PANI films electrodeposited during 10 scans between 0 and +2.5 V/SCE at $5 \mathrm{mV} . \mathrm{s}^{-1}$ (a), $10 \mathrm{mV} \cdot \mathrm{s}^{-1}$ (b), $20 \mathrm{mV} \cdot \mathrm{s}^{-1}$ (c), $50 \mathrm{mV} \cdot \mathrm{s}^{-1}$ (d), $100 \mathrm{mV} \cdot \mathrm{s}^{-1}$ (e), and $200 \mathrm{mV} \cdot \mathrm{s}^{-1}$ (f).

AFM images of the same polymer samples were performed. The AFM image of the PANI sample electrosynthesized at $200 \mathrm{mV}^{-1}$ confirms that the amount of polymer electrodeposited on the Si substrate is low and does not covered the whole Si substrate (Figure 5f). Consequently, it is necessary to perform more scans to obtain a well-defined and sponge-like structure. On the contrary, using a potential scan speed of $100 \mathrm{mV} . \mathrm{s}^{-1}$, or less, 
leads to the formation of a well-defined porous structure as demonstrated in Figure $5 c, 5 d$ and $5 e$, on which the porosity of the film is clearly visible. For the lowest scan speeds ( 5 and $10 \mathrm{mV} \cdot \mathrm{s}^{-1}$ ), the polyaniline amount electrodeposited is so high that the surface is nearly totally covered. Furthermore, the growth of the polymer probably takes place both onto the substrate and into the pores thus decreasing the porosity of the polymer film.

Other PANI films were prepared by varying the number of potential scans from 5 to 15 at the same potential scan speed $\left(100 \mathrm{mV} . \mathrm{s}^{-1}\right)$. All the samples present a porous and sponge-like structure (Supplementary File 2). However, the structure of the thickest polymer film, prepared using 15 scans, is the smoothest one due to the growth of PANI films on the whole substrate and inside the pores of the polymer film. This is concordant with the evolution of the structure when the potential scan speed is varied.

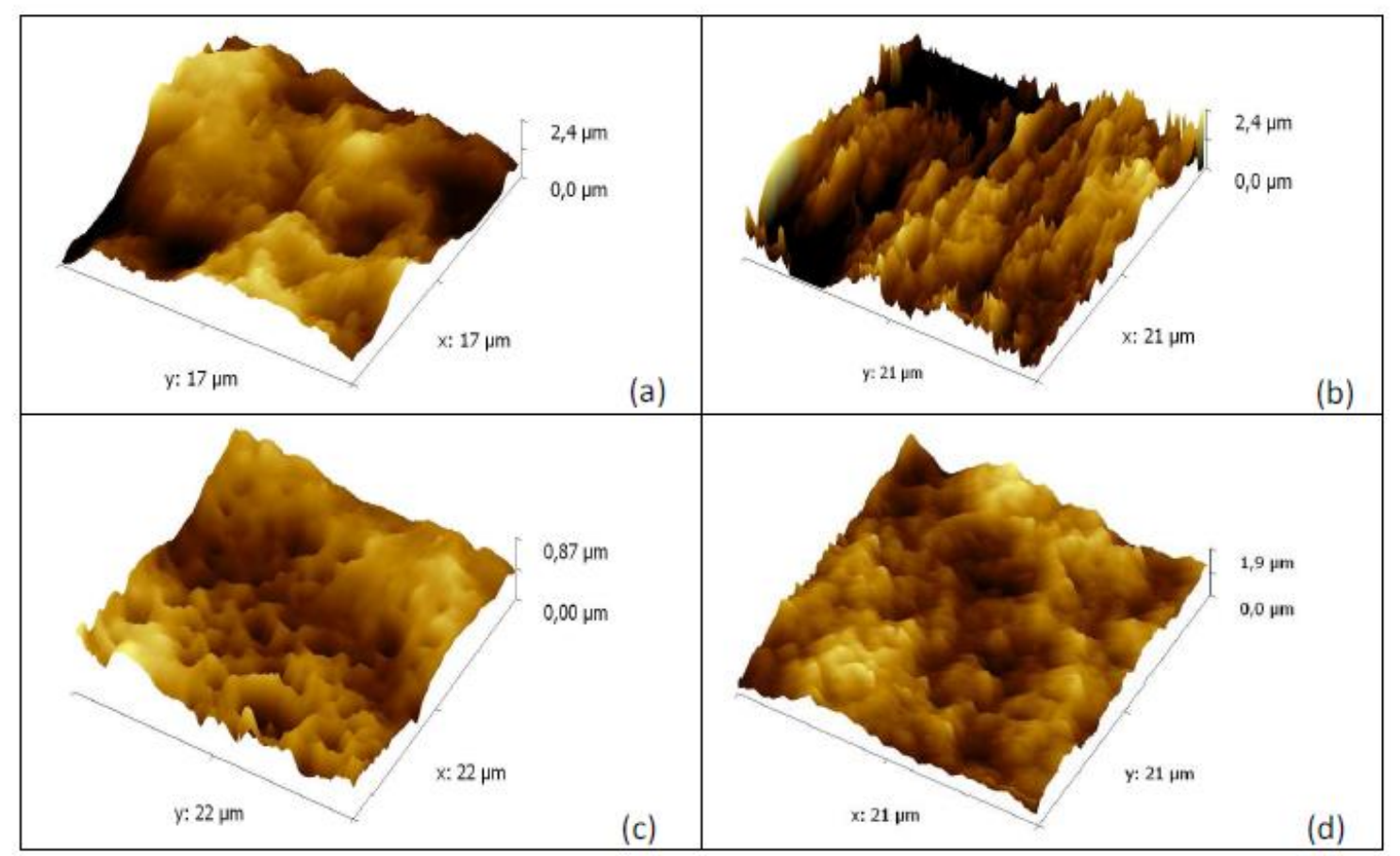




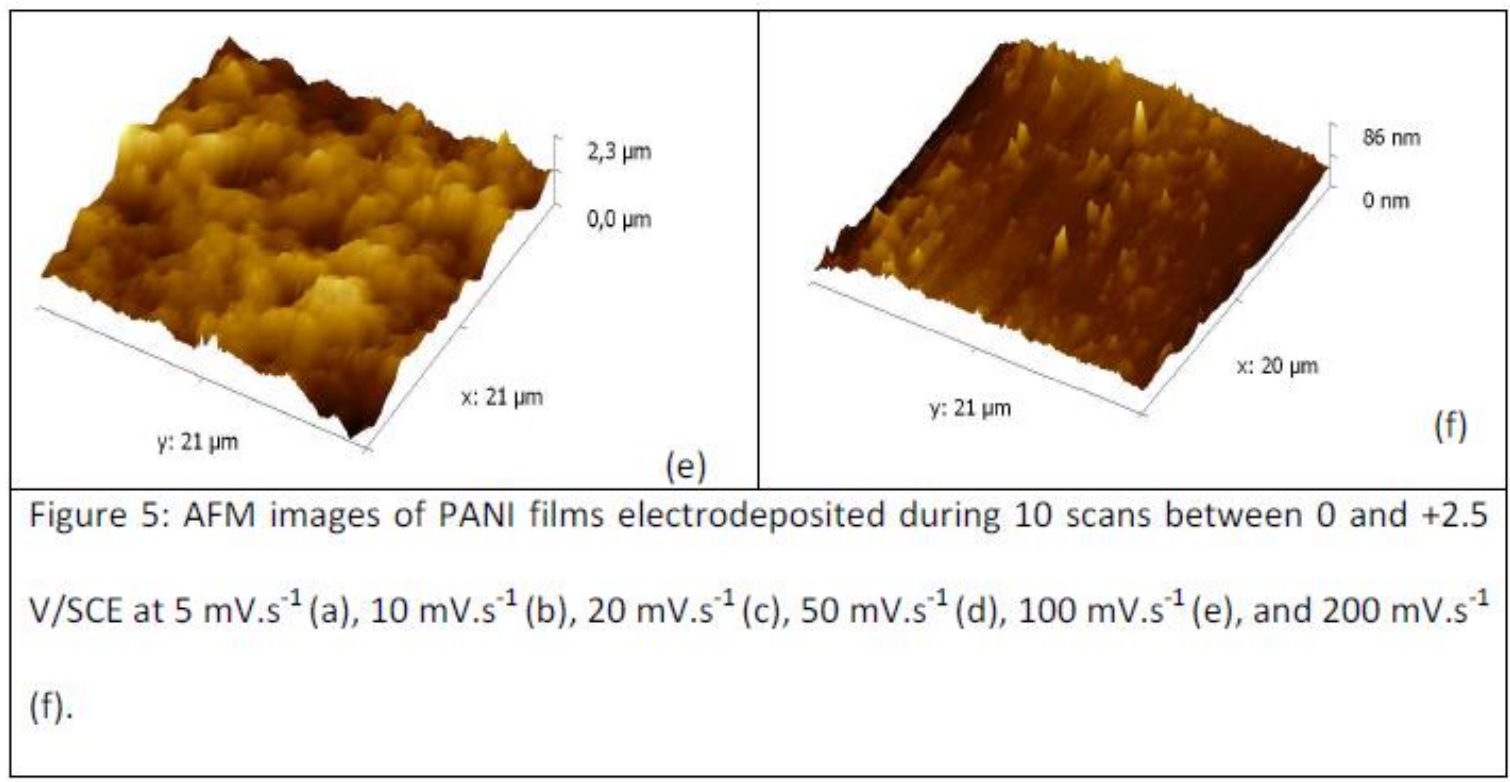

\section{$\square$ Force measurements:}

The adhesion properties of each electrodeposited polyaniline film were estimated through AFM force-distance curves. Experimental pull off forces were comprised between $-49.9 \mathrm{nN}$ and $-181.0 \mathrm{nN}$, depending on the potential scan speed (Table 4). Consequently, these pull off forces are not very different from the ones obtained with PPPD films. This demonstrates the importance of the chemical structure of the polymer in the adhesion properties. Indeed, since both PPPD and PANI are heterocyclic polymers having amino groups, it can be supposed that these amino groups are responsible from the interactions with the sphere and so lead to similar pull off forces. These pull off measurements also confirm that the functionalization of the Si substrates by electrodeposited polymers containing amino groups leads to a strong decrease of the initial adhesion force measured between the cantilever and naked Si substrates. Furthermore, a strong influence of the potential scan speed on the pullof force can be observed in Table 4 since the measured force is increasing when the potential scan rate increases too. The influence of the number of potential scans on the pull off force was also studied (for a potential scan speed of $100 \mathrm{mV} . \mathrm{s}^{-1}$ ). The pull off forces increased with the number of potential scans from - 97.2 and - $130.6 \mathrm{nN}$, and so it can be deduced that the adhesion forces increase with the polymer film thickness, thus demonstrating that the thickness of the PANI film has an influence on the adhesion properties contrary to the thickness of PPPD films that did not impact on the adhesion 
forces. However, it must be noticed that thickness and roughness increase simultaneously, so it is difficult to determine if the increase of the adhesion forces is due to the decrease of the thickness or to the decrease of the roughness of the PANI films. Finally, it can be supposed that the morphology also impact on the adhesion properties. Thus, it is believed that a porous structure is more favorable to the adhesion of the borosilicate sphere to the $\mathrm{Si}$ substrate than a flat and less porous structure. This is confirmed by the low adhesion forces measured for the thickest PANI films that are the less porous due to the growth of PANI inside the pores of the polymer.

\begin{tabular}{|c|c|}
\hline Operating conditions & Pull-off Force \\
\hline naked Si & $1 \mu \mathrm{N}$ \\
\hline $10 \mathrm{mV} . \mathrm{s}^{-1}-10$ scans & $-61.7 \mathrm{nN}$ \\
\hline $20 \mathrm{mV} . \mathrm{s}^{-1}-10$ scans & $-64.0 \mathrm{nN}$ \\
\hline $50 \mathrm{mV} \cdot \mathrm{s}^{-1}-10$ scans & $-91.3 \mathrm{nN}$ \\
\hline $100 \mathrm{mV} \cdot \mathrm{s}^{-1}-10$ scans & $-127.7 \mathrm{nN}$ \\
\hline $200 \mathrm{mV} \cdot \mathrm{s}^{-1}-10$ scans & $-181.0 \mathrm{nN}$ \\
\hline $100 \mathrm{mV} . \mathrm{s}^{-1}-5$ scans & $-97.2 \mathrm{nN}$ \\
\hline $100 \mathrm{mV} . \mathrm{s}^{-1}-15$ scans & $-130.6 \mathrm{nN}$ \\
\hline
\end{tabular}

Table 4: Average measured pull off force values of PANI films.

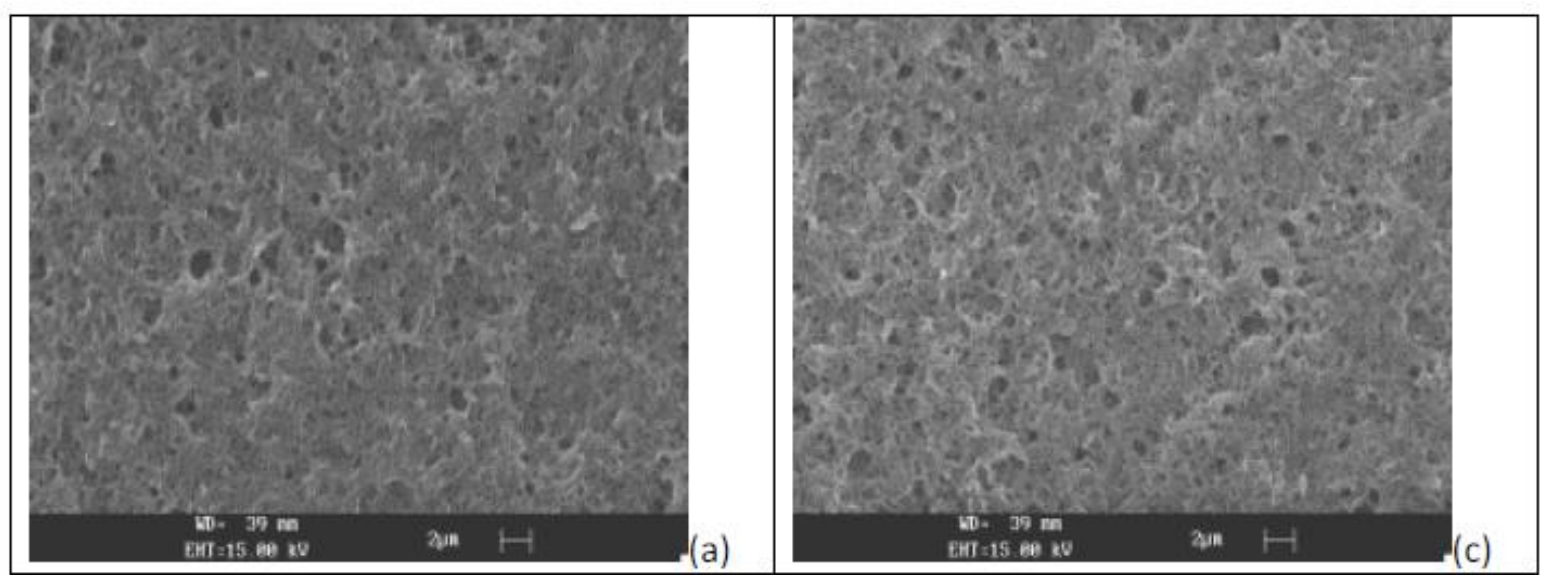




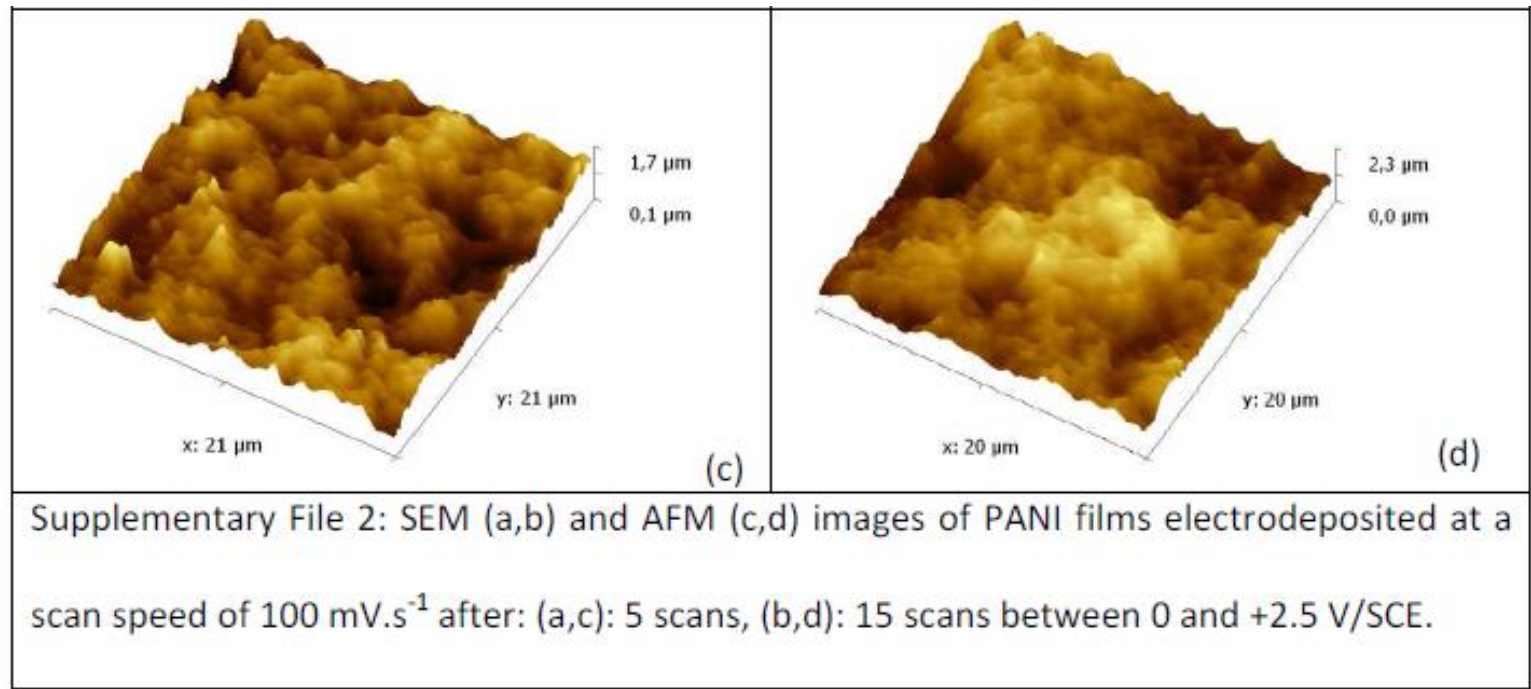

\section{Conclusion}

Polyaniline and poly(p-phenylenediamine), two polymers containing amino groups, were potentiodynamically electrodeposited on Si substrates. Numerous polymer films were electrodeposited to determine the influence of two electrochemical parameters (potential scan speed and number of potential scans) on the film properties. Once the polymer films characterized by infrared spectroscopy, their thickness, roughness and morphology were deeply investigated using profilometry, SEM and AFM. To promote applications in micromanipulation where the adhesion of functionalized objects is the key point, the adhesion forces, measured through AFM force-distance curves, were measured and discussed as a function of the polymer films characteristics. It was demonstrated that the roughness and the morphology of the polymer films strongly impact on the adhesion properties of both electrodeposited polymers, when the thickness influences the adhesion properties of polyaniline but not the ones of poly(p-phenylenediamine). This work also demonstrates that it is possible to control the adhesion of polymer-modified surfaces by easily modifying the electrochemical deposition parameters. Consequently, electropolymerization is a promising strategy to modify surfaces, to drastically decrease or increase force adhesion between a gripper and an object. 


\section{Acknowledgments}

This work was supported by the EU under FAB2ASM (contract FoF-NMP-2010-260079): Efficient and Precise 3D Integration of Heterogeneous Microsystems from Fabrication to Assembly, by the French National Agency (ANR) under NANOROL (contract ANR-07-ROBO0003): The force measurement taken by Atomic Force Microscopy was taken on the "Nanorol platform" (The "Nanorol platform" can be used by external persons. Availability and booking of the station are consultable via internet on: http://nanorol.cnrs.fr/events.php. This work was also supported through the FIMICAP project that is funded by the Région Franche-Comté.

\section{References}

[1] M.G. Hosseini, R. Bagheri, R. Najjar, Electropolymerization of polypyrrole and polypyrrole-ZnO nanocomposites on mild steel and its corrosion protection performance, J. Appl. Polym. Sci., 121 (2011) 3159-3166.

[2] R. Hasanov, S. Bilgic, G. Gece, Experimental and theoretical studies on the corrosion properties of some conducting polymer coatings, J. Solid State Electrochem., 15 (2011) 10631070.

[3] J. Nayak, S.K. Mahadeva, Y. Chen, K.S. Kang, J. Kim, Effect of ionic liquid dispersion on performance of a conducting polymer based Schottky diode, Thin Solid Films, 518 (2010), 5626-5628.

[4] B.C. Kim, C.O. Too, J.S Kwon, J.M. Ko, G.G. Wallace, A flexible capacitor based on conducting polymer electrodes, Synth. Met., 161 (2011) 1130-1132.

[5] M. Knoll, M. Thämer, An enhancement-mode electrochemical organic field-effect transistor, Electrochem. Comm., 13 (2011) 597-599.

[6] H. Pagès, P. Topart, D. Lemordant, Wide band electrochromic displays based on thin conducting polymer films, Electrochim. Acta, 46 (2001) 2137-2143.

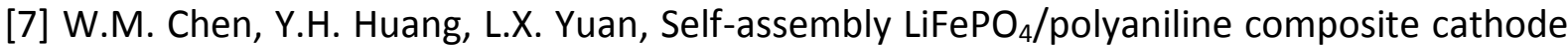
materials with inorganic acids as dopants for lithium-ion batteries, J. Electroanal. Chem., 660 (2011), 108-113. 
[8] C. Wang, W. Zheng, Z. Yue, C.O. Too, G.G. Wallace, Buckled, stretchable polypyrrole electrodes for battery applications, Adv. Mater., 23 (2011) 3580-3584.

[9] V. Erokhin, T. Berzina, P. Camorani, M.P. Fontana, Conducting polymer - Solid electrolyte fibrillar composite material for adaptive networks, Soft Matter, 2 (2006) 870-874.

[10] J.H. Yuan, D.X. Han, Y.J. Zhang, Y.F. Shen, Z.J. Wang, Q.X. Zhang, L. Niu, Electrostatic assembly of polyaniline and platinum-poly(amidoamine) dendrimers hybrid nanocomposite multilayer, and its electrocatalysis towards $\mathrm{CO}$ and $\mathrm{O}_{2}$, J. Electroanal. Chem. 599 (2007) 127135.

[11] J. Han, L. Wang, R. Guo, Facile synthesis of hierarchical conducting polymer nanotubes derived from nanofibers and their application for controlled drug release, Macromol. Rap. Com., 32 (2011) 729-735.

[12] D. Ge, X. Tian, R. Qi, S. Huang, J. Mu, S. Hong, S. Ye, X. Zhang, D. Li, W.A. Shi, Polypyrrole-based microchip for controlled drug release, Electrochim. Acta, 55 (2009) 271275.

[13] H. Yan, K. Tomizawa, H. Ohno, N. Toshima, All-solid actuator consisting of polyaniline film and solid polymer electrolyte, Macromol. Mater. Eng. 288 (2003) 578-584.

[14] U. Lange, V.M. Mirsky, Chemiresistors based on conducting polymers: A review on measurement techniques, Anal. Chim. Acta, 687 (2011) 105-113.

[15] O. Segut, B. Lakard, G. Herlem, J.Y. Rauch, J.C. Jeannot, L. Robert, B. Fahys, Development of miniaturized pH biosensors based on electrosynthesized polymer films, Anal. Chim. Acta, 597 (2007) 313-321.

[16] S. Cosnier, Recent advances in biological sensors based on electrogenerated polymers: A review, Anal. Lett. 40 (2007) 1260-1279.

[17] C. Dhand, M. Das, M. Datta, B.D. Malhotra, Recent advances in polyaniline based biosensors, Biosens. Bioelectron. 26 (2011) 2811-2821.

[18] B. Lakard, D. Magnin, O. Deschaume, G. Vanlancker, K. Glinel, S. DemoustierChampagne, B. Nysten, A.M. Jonas, P. Bertrand, S. Yunus, Urea potentiometric enzymatic biosensor based on charged biopolymers and electrodeposited polyaniline, Biosens. Bioelectron. 26 (2011) 4139-4145. 
[19] L. Liang, J. Liu, C.F. Windisch, G.J. Exarhos, Y.H. Lin, Direct assembly of large arrays of oriented conducting polymer nanowires, Angew. Chem. Int. Ed., 41 (2002) 3665-3668.

[20] H.N. Dinh, V.I. Birss, Effect of substrate on polyaniline film properties a cyclic voltammetry and impedance study, J. Electrochem. Soc. 147 (2000) 3775-3784.

[21] H.H. Zhou, S.Q. Jiao, J.H. Chen, W.Z.Wei, Y.F. Kuang, Relationship between preparation conditions, morphology and electrochemical properties of polyaniline prepared by pulse galvanostatic method (PGM), Thin Solid Films 450 (2004) 233-239.

[22] Y.P. Guo, Y. Zhou, Polyaniline nanofibers fabricated by electrochemical polymerization: A mechanistic study, Eur. Polym. J 43 (2007) 2292-2297.

[23] S. Carquigny, O. Segut, B. Lakard, F. Lallemand, P. Fievet, Effect of electrolyte solvent on the morphology of polypyrrole films: Application to the use of polypyrrole in $\mathrm{pH}$ sensors, Synth. Met. 158 (2008) 453-461.

[24] T. Patois, B. Lakard, S. Monney, X. Roizard, P. Fievet, Characterization of the surface properties of polypyrrole films: influence of electrodeposition parameters, Synth. Met. 161 (2011) 2498-2505.

[25] A.G. MacDiarmid, A.J. Epstein, Polyanilines: A novel class of conducting polymers, Faraday Discuss. Chem. Soc. 88 (1989) 317-332.

[26] W.S. Huang, B.H. Humphrey, A.G. MacDiarmid, Polyaniline, a novel conducting polymer. Morphology and chemistry of its oxidation and reduction in aqueous electrolytes, J. Chem. Soc. Faraday Trans. 182 (1986) 2385-2400.

[27] C.C. Buron, B. Lakard, A.F. Monnin, V. Moutarlier, S. Lakard, Elaboration and characterization of polyaniline films electrodeposited on tin oxides, Synth. Met., 161 (2011) 2162-2169.

[28] N. Plesu, A. Kellenberger, M. Mihali, N. Vaszilcsin, Effect of temperature on the electrochemical synthesis and properties of polyaniline films, J. Non-Crystal. Solids, 356 (2010) 1081-1088.

[29] X.Y. Peng, F. Luan, X.X. Liu, D. Diamond, K.T. Lau, pH-controlled morphological structure of polyaniline during electrochemical deposition, Electrochim. Acta, 54 (2009) 6172-6177.

[30] Q. Hao, W. Lei, X. Xia, Z. Yan, X. Yang, L. Lu, X. Wang, Exchange of counter anions in electropolymerized polyaniline films, Electrochim. Acta, 55 (2010) 632-640. 
[31] B. Lakard, G. Herlem, S. Lakard, B. Fahys, Ab initio study of the polymerization mechanism of poly(p-phenylenediamine, J. Molec. Struct: THEOCHEM, 638 (2003) 177-187. [32] D.M. Zhou, Y.Q. Dai, K.K. Shiu, Poly(phenylenediamine) film for the construction of glucose biosensors based on platinized glassy carbon electrode, J. Appl. Electrochem. 40 (2010) 1997-2003.

[33] Y.Q. Dai, D.M. Zhou, K.K. Shiu, Permeability and permselectivity of polyphenylenediamine films synthesized at a palladium disk electrode, Electrochim. Acta 52 (2006) 297-303.

[34] I. Tapsoba, S. Bourhis, T. Feng, M. Pontié, Sensitive and selective electrochemical analysis of methyl-parathion (MPT) and 4-nitrophenol (PNP) by a new type $p-N i T S P c / p-P P D$ coated carbon fiber microelectrode (CFME), Electroanalysis 21 (2009) 1167-1176.

[35] S.M. Sayyah, S.S. Abd El-Rehim, M.M. El-Deeb, S.M. Kamal, R.E. Azooz, Elecropolymerization of $\mathrm{p}$-phenylenediamine on Pt-electrode from aqueous acidic solution: kinetics, mechanism, electrochemical studies, and characterization of the polymer obtained, J. Applied Polym. Sci. 117 (2010) 943-952.

[36] A.F.L.O.M. Santos, M.A.V. Ribeiro Da Silva, Diaminobenzenes: An experimental and computational study, Journal of Physical Chemistry B, 115 (2011) 4939-4948.

[37] E. Akalin, S. Akyuz, Theoretical study of IR spectra of paraphenylenediamine, Vibr. Spectrosc., 22 (2000) 3-10.

[38] O. Segut, G. Herlem, B. Lakard, V. Blondeau-Patissier, M. Nardin, S. Gree, J.Y. Rauch, Electrochemically deposited polyethyleneimine films and their characterization, Synth. Met. 160 (2010) 1359-1364.

[39] B. Lakard, G. Herlem, B. Fahys, Ab initio study of the electrochemical polymerization mechanism of w-diamines, J. Chem. Phys. 115 (2001) 7219-7226.

[40] S.L. Mu, J.Q. Kan, Evidence for autocatalytic polymerization of aniline, Electrochim. Acta, 41 (1996) 1593-1599.

[41] N. Plesu, A. Kellenberger, M. Mihali, N. Vaszilcsin, Effect of temperature on the electrochemical synthesis and properties of polyaniline films, Journal of Non-Crystalline Solids 356 (2010) 1081-1088. 
[42] S.Y. Cui, S.M. Park, Electrochemistry of conductive polymers XXIII: polyaniline growth studied by electrochemical quartz crystal microbalance measurements, Synth. Met., 105 (1999) 91-98. 


\section{Table and Figure Captions:}

Figure 1: Cyclic voltammogram of: (a) $0.1 \mathrm{M} \mathrm{PPD}$ in pH 7.0 phosphate buffer solution, (b) 0.4 $\mathrm{M}$ aniline in $1.2 \mathrm{M} \mathrm{HCl}$ solution, at a Si electrode, scan speed: $100 \mathrm{mV} \mathrm{s}^{-1}$.

Figure 2: SEM images of PPPD films electrodeposited during 10 scans at $50 \mathrm{mV}^{-1}{ }^{-1}$ (a), 100 $m V \cdot s^{-1}(b), 160 m V \cdot s^{-1}$ (c), and $200 m V \cdot s^{-1}(d)$.

Figure 3: AFM images of PPPD films electrodeposited during 10 scans between 0 and +2.5 V/SCE at $50 \mathrm{mV} . \mathrm{s}^{-1}$ (a), $100 \mathrm{mV} . \mathrm{s}^{-1}$ (b), $160 \mathrm{mV} . \mathrm{s}^{-1}$ (c), and $200 \mathrm{mV} . \mathrm{s}^{-1}$ (d).

Figure 4: SEM images of PANI films electrodeposited during 10 scans between 0 and +2.5 V/SCE at $5 \mathrm{mV} . \mathrm{s}^{-1}$ (a), $10 \mathrm{mV} . \mathrm{s}^{-1}$ (b), $20 \mathrm{mV} . \mathrm{s}^{-1}$ (c), $50 \mathrm{mV} . \mathrm{s}^{-1}$ (d), $100 \mathrm{mV} . \mathrm{s}^{-1}$ (e), and $200 \mathrm{mV} . \mathrm{s}^{-1}$ (f).Figure 5: AFM images of PANI films electrodeposited during 10 scans between 0 and +2.5 V/SCE at the following scan speeds: (a): $5 \mathrm{mV} \cdot \mathrm{s}^{-1}$, (b): $10 \mathrm{mV} \cdot \mathrm{s}^{-1}$, (c): $20 \mathrm{mV} \cdot \mathrm{s}^{-1}$, (d) $50 \mathrm{mV} \cdot \mathrm{s}^{-1}$, (e) $100 \mathrm{mV} \cdot \mathrm{s}^{-1}$, (f) $200 \mathrm{mV} \cdot \mathrm{s}^{-1}$.

Table 1: Infrared vibration bands of oxidized PPD and aniline.

Table 2: Thickness and roughness of electrodeposited poly(p-phenylenediamine) films.

Table 3: Average measured pull off force values of PPPD films.

Table 4: Average measured pull off force values of PANI films.

Supplementary File 1: SEM $(a, b)$ and $\operatorname{AFM}(c, d)$ images of PPPD films electrodeposited at a scan speed of $100 \mathrm{mV} . \mathrm{s}^{-1}$ after: $(\mathrm{a}, \mathrm{c})$ : 5 scans, $(\mathrm{b}, \mathrm{d}): 15$ scans between 0 and $+2.5 \mathrm{~V} / \mathrm{SCE}$.

Supplementary File 2: $\operatorname{SEM}(a, b)$ and $\operatorname{AFM}(c, d)$ images of PANI films electrodeposited at a scan speed of $100 \mathrm{mV} \cdot \mathrm{s}^{-1}$ after: $(\mathrm{a}, \mathrm{c}): 5$ scans, $(\mathrm{b}, \mathrm{d})$ : 15 scans between 0 and $+2.5 \mathrm{~V} / \mathrm{SCE}$. 